Z Epileptol 2018 $\cdot 31: 179-184$ https://doi.org/10.1007/s10309-018-0192-z Published online: 23 May 2018 (C) The Author(s) 2018

CrossMark

\author{
R. Kreidenhuber ${ }^{1} \cdot$ G. Demarchi ${ }^{2} \cdot$ G. Kalss ${ }^{1} \cdot$ M. Leitinger ${ }^{1}$ P. A. Winkler ${ }^{3} \cdot$ \\ E. Trinka ${ }^{1,4} \cdot$ S. Rampp ${ }^{5,6}$ \\ ' Department of Neurology, Christian-Doppler-Klinik, Paracelsus Medical University of Salzburg, Salzburg, \\ Austria \\ ${ }^{2}$ Ongoing Brain Oscillations and Behavior Lab, Paris Lodron University Salzburg, Salzburg, Austria \\ ${ }^{3}$ Department of Neurosurgery, Christian-Doppler-Klinik, Paracelsus Medical University of Salzburg, \\ Salzburg, Austria \\ ${ }^{4}$ Centre for Cognitive Neuroscience, Salzburg, Austria \\ ${ }^{5}$ Department of Neurosurgery, University Hospital Erlangen, Erlangen, Germany \\ ${ }^{6}$ Department of Neurosurgery, University Hospital Halle (Saale), Halle (Saale), Germany
}

\title{
Benefit of magnetic source localization in challenging refractory epilepsies
}

positron emission tomography (FDGPET), single-photon emission computed tomography (SPECT), and neuropsychological testing. If there is a clear supposition of an EZ accessible to surgery, the hypothesis is proven via intracranial EEG recordings (iEEG). Outcome strongly depends on the type of surgery and its location, with a chance of seizure freedom after 1 year of $66 \%$ for temporal lobe epilepsy, $46 \%$ for parietal and occipital lobe epilepsy, but only $27 \%$ in frontal lobe epilepsy [37].

Magnetoencephalography (MEG) or magnetic source imaging (MSI) is one of the newer additions to the presurgical work-up $[32,38]$. Source localization of the epileptogenic or irritative zone and functional mapping are the two main clinical applications. The present article focuses on MEG for epileptic focus localization, one of the main clinical applications in epileptology. With increasing availability and routine use in epilepsy centers in Europe [7, 20], worldwide evidence for the usefulness of MEG is constantly growing.

The American Clinical Magnetoencephalography Society (ACMEGS) released guidelines on the conduction and analysis of clinical MEG recordings and defined minimum standards for adequate clinical use of MEG [4]. In accordance

with ACMEGS guidelines [4], clinical analysis usually includes source localization via a single equivalent current dipole model [7] in respect to dipole localization, - orientation and propagation patterns-each contributing to the final identification of the seizure onset zone, the implantation plan, and the predicted outcome. MEG and EEG show differences in epileptic spike yields because of the number of sensors used, the source depth and orientation, the background activity (signal-to-noise ratio), and the smearing of the potential fields owing to variations in skull resistivity in EEG [12]. Spike yields for temporal sources are comparable between scalp EEG and MEG, whereas MEG shows a higher (= better) signal-to-noise ratio in the frontal area [12]. Owing to the complementary nature of the modalities, simultaneous EEG is oftentimes recorded and analyzed [2].

\section{Objectives}

This article provides an overview of the current evidence concerning the impact of MEG on the management of epilepsy patients who are "clinically difficult" cases Its role and its importance compared with other noninvasive and invasive methods are addressed. The main focus is on the benefit provided for presurgical evalua- monitoring, magnetic resonance imaging (MRI), [18 F]fluorodeoxyglucose- 

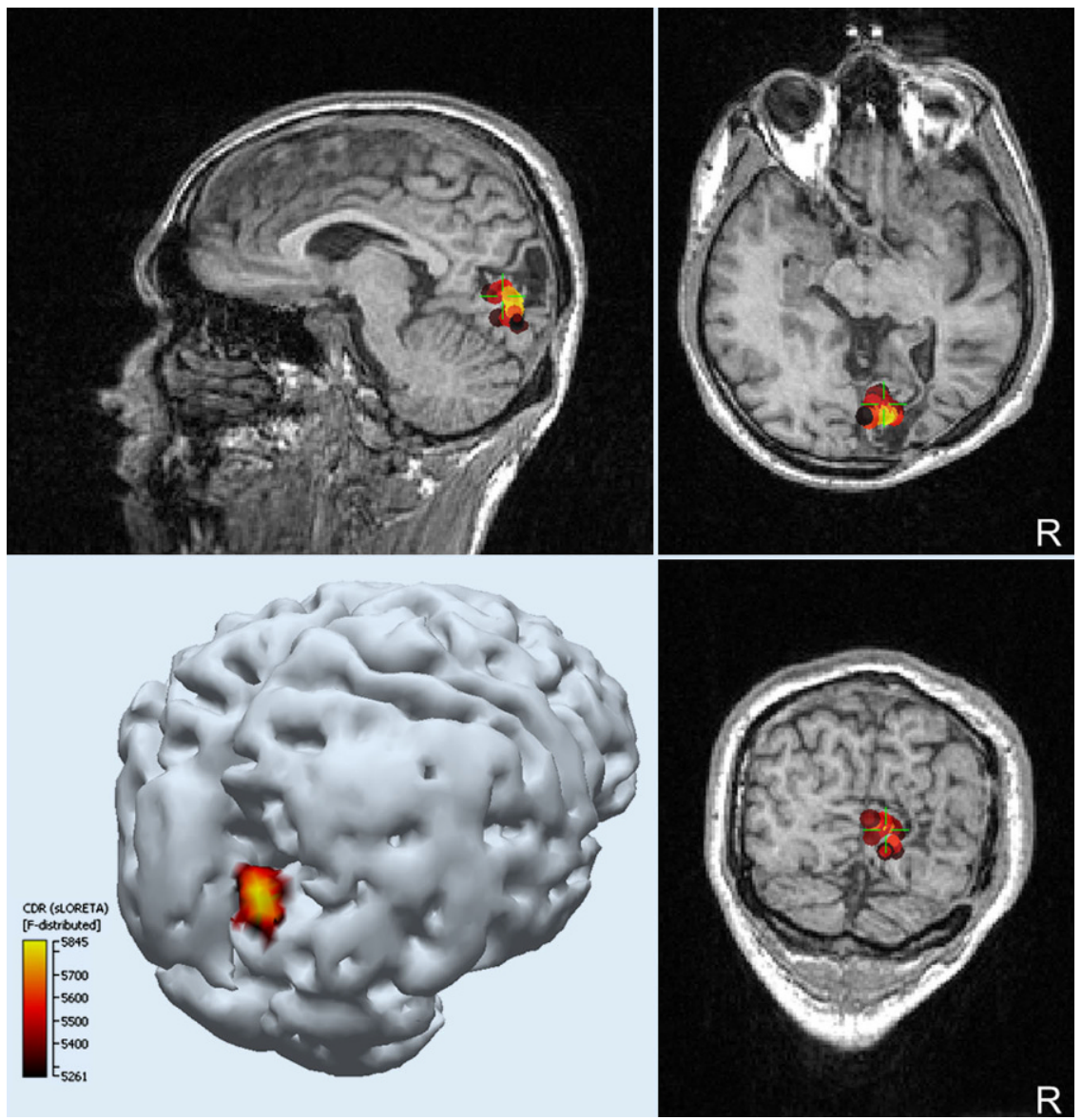

Fig. $1 \Delta$ Magnetic source imaging results (sLoreta) of averaged interictal spikes in a patient with recurring seizures after previous surgery. Second surgery including the magnetoencephalography localization resulted in seizure freedom

tion in terms of EZ localization as well as the identification of outcome predictors.

\section{Methods}

An extensive Medline literature search (on 27 December 2017) for studies published from 1990 was conducted using the following search terms (in various combinations): magnetoencephalography, MEG, value, outcome, epilepsy surgery, refractory, benefit, MSI, source localization, source analysis, and seizure. The search results were screened based on article summaries. References were further examined to identify additional relevant articles. Studies were considered for inclusion if they reported on patient groups of more than ten individuals, showed clinically relevant results, provided sufficient outcome data, or compared MEG with other routinely used methods.

\section{Results}

\section{Overall benefit}

Most studies have shown an overall influence of MEG on the clinical course of patients with epilepsy in about $21-35 \%$ of cases $[6,30]$. This impact does not apply for all patients homogeneously but changes according to brain region and presence or absence of a lesion.

\section{Temporal lobe epilepsy}

In temporal lobe epilepsy (TLE), MEG spike yield depends on the location of the EZ. Compared with other temporal locations, MEG sensitivity is lowest in mesial TLE. Sensitivity is highest in extratemporal neocortical epilepsy [39]. Because of the well-defined semiology and characteristic interictal/ictal EEG findings, the definition of an EZ is oftentimes feasible without extensive further diagnos- tics-especially in the presence of a lesion such as concordant hippocampal sclerosis.

If there is no evidence of a lesion or if electrophysiological findings are pathological on both hemispheres, however, MEG may reveal the side of the EZ or suggest temporal propagation of an extratemporal source $[18,24]$.

In mesial TLE, MEG spike propagation patterns are correlated with postoperative seizure freedom: Restricted anterior/mesial leading patterns were associated with postoperative Engel class I, but temporoparietal propagation was indicative of persisting seizures (class II-IV; [36]).

\section{Frontal lobe epilepsy}

Frontal lobe epilepsy (FLE) is one of the most diagnostically challenging forms of focal epilepsy with the least favorable overall surgical outcome-only $10 \%$ of patients achieve lasting seizure freedom [37]. These odds seem to improve if MEG results are concordant with the resected area:

$\mathrm{Mu}$ et al. [21] conducted a retrospective analysis of 46 surgically treated patients with FLE who underwent preoperative MEG. They found a higher rate of overall (and also long lasting) seizure freedom in patients with complete resection of dipole clusters, whereas multifocal localization resulted in persisting seizures in all seven patients with this pattern.

Genow et al. [9] assessed MEG spike localizations in respect to surgical outcome in lesional FLE. Good surgical outcome was found in patients with the majority of spikes located within the resected brain volume.

The impact of MEG-guided epilepsy surgery with the aid of neuronavigation and intraoperative MRI on seizure outcome of 28 nonlesional FLE patients was investigated by Sommer and colleagues [28]. In this series using multimodal neuronavigation, seizure control rates (50-64\%) and the probability of complete resection of the MEG localizations were similar to lesional FLE at a mean follow-up of 70.3 months (12-284).

Stefan and coworkers [33] analyzed 39 patients with FLE. Patients with a sin- 
Z Epileptol 2018 ·31:179-184 https://doi.org/10.1007/s10309-018-0192-z

(c) The Author(s) 2018

R. Kreidenhuber - G. Demarchi · G. Kalss - M. Leitinger · P. A. Winkler · E. Trinka - S. Rampp

Benefit of magnetic source localization in challenging refractory epilepsies

Abstract

Background. About 23 million people worldwide suffer from medically refractory epilepsy. Surgery might be the best treatment option with a reasonable chance of seizure freedom. Surgical success depends on the exact definition of the epileptogenic zone (EZ). Magnetoencephalography (MEG) is one of the newer additions to the noninvasive presurgical work-up.

Objectives. This study gives an overview of the impact of MEG on the management of epilepsy patients, focusing on (1) the influence on presurgical evaluation, (2) the identification of patients with the greatest benefit, and (3) possible surgical outcome predictors.

Methods. An extensive Medline literature search was conducted for studies published from 1990.
Results. MEG is in clinical use in the presurgical evaluation of epilepsies for the identification of the EZ and outcome prediction. In cases of failed surgery, it serves as a means to locate the remaining epileptogenic cortex. The usefulness of MEG has been reported for a wide range of localizations including challenging areas like the insula. In cases of multiple possible culprit lesions, MEG can mark the epileptogenic lesion, whereas in cases of nonlesional magnetic resonance imaging (MRI) findings, MEG can pinpoint a lesional or nonlesional epileptogenic cortex area. The role of MEG in the presurgical evaluation of epilepsy was shown with rates of modified approaches in $20-35 \%$ of cases. This holds true especially for cases with extratemporal epilepsy.
Discussion. The value of MEG source localization is highest in extratemporal epilepsy, in MRI-negative or multilesional cases, if other modalities yield contradictory or inconclusive results, or in cases of suspected multifocal epilepsy. There is clear evidence that MEG yields nonredundant information and influences the therapeutic course of patients. Various patient groups likely to benefit from MEG were identified. Considering the poor chances of seizure freedom with continued medical treatment, these patients should not be denied source localization, which could result in surgery with favorable outcomes.

Keywords

MEG · MSI · Epilepsy · Refractory · Epilepsy surgery

\section{Diagnostischer Beitrag der MEG - Quellenlokalisation in Fällen therapierefraktärer Epilepsie}

Zusammenfassung

Hintergrund. Etwa 23 Mio. Menschen weltweit leiden unter therapierefraktärer Epilepsie. Ein chirurgischer Eingriff stellt hier oft die beste Behandlungsmethode mit realistischen Chancen auf Anfallsfreiheit dar. Der Grundstein einer erfolgreichen Operation wird hier durch die korrekte Lokalisierung der Anfallsursprungszone (epileptogene Zone, EZ) gelegt. Die Magnetenzephalographie (MEG) gehört zu den neueren Ergänzungen der nichtinvasiven prächirurgischen Abklärung. Zielsetzung. Diese Arbeit gibt einen Überblick zur MEG-Diagnostik von Patienten mit schwer behandelbarer Epilepsie. Der Fokus liegt auf (1) dem Einfluss auf die Entscheidungsfindung im Rahmen der prächirurgischen Abklärung,

(2) der Identifikation der am meisten von der MEG profitierenden Patienten sowie (3) möglichen Prädiktoren für postoperative Anfallsfreiheit.
Methoden. Es erfolgte eine extensive Literaturrecherche (MEDLINE) unter Einschluss von Studien ab 1990.

Ergebnisse. Die MEG kommt sowohl im prächirurgischen (Identifikation der EZ) als auch im postchirurgischen Bereich (Lokalisierung verbliebener/neuer EZ) zum Einsatz. Ein entsprechender Nutzwert wurde bereits für eine Vielzahl von problematischen neokortikalen oder auch tiefer gelegenen Lokalisationen bestätigt. Im Fall mehrerer potenziell anfallsauslösender Läsionen in der Magnetresonanztomographie (MRT) markiert die MEG epileptogene Läsionen. Bei fehlendem Läsionsnachweis in der MRT kann die MEG zum Nachweis subtiler Läsionen führen, oder es lassen sich damit nichtläsionelle Kortexzonen als EZ identifizieren. Ein signifikanter Einfluss der MEG auf die prächirurgische Abklärung wird in 20-35\% der Fälle angegeben, wobei dieser in extratemporalen Epilepsieformen höher als $35 \%$ ist.

Diskussion. Der Nutzen der MEG ist bei extratemporalen Epilepsieformen, nichtläsioneller und multiläsioneller MRT, im Fall nicht wegweisender oder widersprüchlicher anderer Befunde und bei Verdacht auf multifokale Epilepsien am höchsten. In diesen Fällen sollte die MEG niederschwellig zur Anwendung kommen. Oft kann eine Prognose in Bezug auf die Chancen auf postoperative Anfallsfreiheit abgeben werden. Es zeigt sich klare Evidenz, dass die MEG Zusatzinformationen bei Patienten mit therapierefraktärer Epilepsie liefert und damit die Chancen auf einen günstigen Operationsausgang erhöht.

Schlüsselwörter

MEG · MSI · Epilepsie · Refraktär · Epilepsiechirurgie gle focus had better postoperative outcomes than did patients with multiple foci. MEG source localizations close to a lesion marked the lesion or its surrounding network as epileptogenic.

\section{Opercular/insular epilepsy}

Insular epilepsy poses a diagnostic challenge as it can mimic parietal, temporal, or frontal lobe epilepsies [23, 27]. MEG may contribute to the identification of epileptogenic lesions in such deep periinsular areas even when multiple previous methods have failed $[10,13]$. In the absence of a lesion or other conclusive noninvasive localizing information, MEG may still enable identification of surgery candidates $[10,13,18]$. In mostly small case series it was shown that MEG may detect spike populations from insular generators not seen or misleadingly localized in EEG. The resulting correct 


\section{Table 1 Selected studies and key results}

\begin{tabular}{|l|l|l|}
\hline Study & Design & Key results \\
\hline $\begin{array}{l}\text { Sutherling et al. } \\
{[35]}\end{array}$ & $\begin{array}{l}\text { Prospective, } \\
\text { blinded, } \\
\text { crossover- } \\
\text { controlled }\end{array}$ & $\begin{array}{l}\text { 1. MSI clearly benefited 9\% of total study population } \\
\text { (=21\% of patients who underwent resection) }\end{array}$ \\
$\begin{array}{l}\text { 2. Avoidance of bilateral implantation in 2 patients, } \\
\text { both resected with Engel I outcome }\end{array}$ \\
\hline $\begin{array}{l}\text { Knowlton et al. } \\
{[16]}\end{array}$ & Prospective & $\begin{array}{l}\text { 1.MSI indicated additional electrode coverage in 23\% } \\
\text { of patients. Additional electrodes sampled the EZ in } \\
\text { 39\% }\end{array}$ \\
\hline $\begin{array}{l}\text { Knowlton et al. } \\
{[14]}\end{array}$ & Prospective & $\begin{array}{l}\text { 1. The positive predictive value of MSI for seizure local- } \\
\text { associated with seizure- free outcome }\end{array}$ \\
\hline
\end{tabular}
[14]

Knowlton et al. Prospective [15]

Stefan et al. [30] Retrospective

Bagić et al. [3] Review

De Tiège et al. [6] Prospective, blinded, bicenter

2. The kappa score of agreement for MSI with iEEG was $0.2744(p<0.01)$

1. MSI sensitivity for a conclusively localized study was $55 \%$ with a positive predictive value of $78 \%$. Eliminating nondiagnostic MSI cases (no spikes captured during recording) yielded a corrected negative predictive value of $64 \%$. With available comparison subgroups FDG-PET and ictal SPECT values were similar to MSI

1. The average sensitivity of MEG for specific epileptic activity was $70 \%$

2. MSI identified the lobe to be treated in $89 \%$, with results for extratemporal cases being even superior to those with temporal lobe surgery

3. MSI supplied additional information in $35 \%$ and information crucial to final decision-making in $10 \%$ of cases

1. MSI can increase the diagnostic yield of MRIs

2. MSI-guided re-review of presumed negative MRIs may reveal significant pathology including focal cortical dysplasia

1. MSI changed the initial management in $21 \%$ of patients

2. MSI-related changes were significantly more frequent in patients with presumed extratemporal or undetermined localization epilepsy compared with patients with presumed temporal epilepsy $(p \leq 0.001)$

3. Changes due to MSI had a clear impact on clinical management in $13 \%$ of all patients

EZ epileptogenic zone, iEEG intracranial electroencephalography, FDG-PET [18F]fluorodeoxyglucosepositron emission tomography, MEG magnetoencephalography, $M R I$ magnetic resonance imaging, MSI magnetic source imaging, SPECT single-photon emission computed tomography, TLE temporal lobe epilepsy

identification of the seizure-onset zone can lead to good surgical outcomes with Engel class I outcome reported in $67 \%$ of patients [1] or even as high as $87 \%$ in cases of corresponding tight dipole clusters [18].

\section{Lesional vs. nonlesional vs. multilesional epilepsy}

In contrast to cases with lesional epilepsies, the outcome of epilepsy surgery is generally worse when MRI is unremark- otherwise missed in routine work-up [3, $11]$.

In "nonlesional" epilepsy, Wang et al. [40] evaluated the additional value of MRI postprocessing (PP) and MEG. Of the 12 patients with subtle changes in $\mathrm{PP}$, there were seven with concordant MSI findings, who also presented with significantly better surgical outcome.

In patients with extratemporal neocortical focal epilepsy with nonlesional MRI, MSI seems to outperform FDGPET in seizure-onset zone localization [39].

MEG helps to distinguish epileptogenic from nonepileptogenic lesions if multiple brain lesions are identified on MRI studies [31].

\section{Contributions for phase II work-up}

MEG adds valuable and nonredundant information for successful planning of intracranial recordings leading to a correct localization of the seizure-onset zone in $50-80 \%$ of cases $[14,15,30]$. Knowlton et al. [16] investigated the effect of MEG on electrode placement for invasive recordings. In a total of $160 \mathrm{pa}$ tients, MEG results indicated additional electrode coverage in 18 of 77 patients undergoing iEEG (23\%). iEEG seizure onsets involved these newly added electrodes in 39\% of cases. The presence of only a single highly localized dipole cluster was significantly associated with seizure-free outcome in all operated patients (mean follow-up of 3.4 years).

The influence of MEG source localization on the planning of iEEG was also assessed by Sutherling and coworkers [35] in a series of 69 sequential patients. MEG provided nonredundant information for 23 patients $(33 \%)$. In terms of surgical planning, it added iEEG electrodes in nine $(13 \%)$ and changed the implantation approach in 14 individuals (20\%). On the basis of MEG findings, 16 patients (23\%) were scheduled for different iEEG coverage: 28 patients underwent iEEG, 29 underwent resection, and 14 proceeded to vagal nerve stimulation. In 17 patients (24\%), MEG changed the clinical decision. MEG led to contralateral electrodes being avoided in two patients. 
Stefan et al. [30] published a retrospective analysis of 455 epilepsy patients with MEG source localization. Among 131 patients who underwent surgical therapy, MEG identified the lobe to be treated in $89 \%$, with results for extratemporal cases being superior to those with temporal lobe surgery. MEG supplied additional information in 35\% and information crucial to final decision-making in $10 \%$ of cases. The accuracy and the additive contribution of findings underlined its appropriateness especially for extratemporal epilepsies.

\section{Postsurgical evaluation}

Resective epilepsy surgery may fail because of a number of reasons including incomplete resection, incorrect localization of the seizure-onset zone, presence of additional seizure-onset zones, or progression of an underlying disease. Overall, around $4-14 \%$ of patients have a second operation with about one third of the patient population being seizure free afterward [34].

In many patients with persistent refractory seizures after surgery, MEG can give valuable information in terms of localizing the remaining epileptogenic tissue. Second surgeries in patients with persistent spike clusters adjacent to or within the former resection margin (- Fig. 1) lead to favorable surgical outcome, whereas distributed epileptiform activity should be further evaluated [19, 22].

\section{Discussion}

MEG influences the clinical management of refractory epilepsy in the presurgical and postsurgical phase, as summarized in - Table 1. The value of MSI is highest in extratemporal epilepsy, in MRI-negative or multilesional cases, and if other modalities yield results that are contradictory, inconclusive, or multifocal.

MEG guides placement of electrodes for iEEG recordings and minimizes secondary implantation of additional electrodes. In many patient populations, there is a strong correlation between MEG findings and surgical outcome with higher rates of seizure freedom especially in extratemporal cases with concordant MEG results.

As holds true for other methods in presurgical evaluation (SPECT, PET, electric source imaging etc.), the cost of hardware (and software), running costs, and the cost of personnel might be limiting factors for the adoption and spread of MEG in clinical use.

Application of MSI provides nonredundant information and clearly influences the therapeutic course taken in a significant proportion of patients. Specific indications with clear benefit for the examined patients have been identified. Considering the poor chances of seizure freedom with continued medical treatment, these patients should be offered source localization, which may enable successful surgery.

It should be a priority to generate further evidence assisting in proper patient selection. Limitations of current studies include small sample size and selection bias (oftentimes highly preselected or otherwise unclear cases are referred to MEG). These restrictions could be addressed by prospective multicenter efforts with blinded outcome assessment [32]. Despite growing use worldwide, it is to be expected that not every epilepsy center will (or should) offer MEG. This should of course not lead to a restriction of referral to MEG for patients who could potentially benefit from it. Access can only be guaranteed if candidates are clearly identified and collaborative networks are formed in order to ensure access to MSI regardless of local availability.

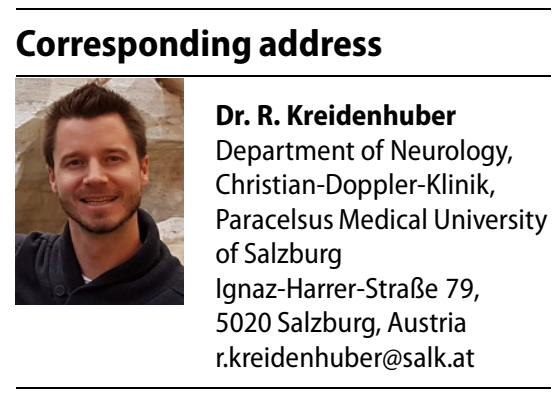

Funding. Open access funding provided by Paracelsus Medical University.

\section{Compliance with ethical guidelines}

Conflict of interest. S. Rampp is a member of the board of directors of the European MEG Society (EMEGS) and of the International Society for the Advancement of Clinical MEG (ISACM). In line with a consultancy agreement with Elekta Oy, Helsinki, Finland, he holds training courses on clinical MEG/EEG. R. Kreidenhuber, G. Demarchi, G. Kalss, M. Leitinger, P.A Winkler and E. Trinka declare that they have no competing interests.

This article does not contain any studies with human participants or animals performed by any of the authors.

Open Access. This article is distributed under the terms of the Creative Commons Attribution 4.0 International License (http://creativecommons.org/licenses/by/ 4.0/), which permits unrestricted use, distribution, and reproduction in any medium, provided you give appropriate credit to the original author(s) and the source, provide a link to the Creative Commons license, and indicate if changes were made.

\section{References}

1. AhmedR, OtsuboH, Snead Cetal (2017) Diagnostic evaluation and surgical management of pediatric insular epilepsy utilizing magnetoencephalography and invasive EEG monitoring. Epilepsy Res 140:72-81. https://doi.org/10.1016/j.eplepsyres. 2017.12.011

2. Aydin Ü, Vorwerk J, Dümpelmann M et al (2015) Combined EEG/MEG can outperform single modality EEG or MEG source reconstruction in presurgical epilepsy diagnosis. PLoS ONE 10:e118753. https://doi.org/10.1371/journal. pone. 0118753

3. Bagić A (2016) Look back to leap forward: The emerging new role of magnetoencephalography (MEG) in nonlesional epilepsy. Clin Neurophysiol Off J Int Fed Clin Neurophysiol 127:60-66. https:// doi.org/10.1016/j.clinph.2015.05.009

4. Bagić Al, Knowlton RC, Rose DF et al (2011) American Clinical Magnetoencephalography Society Clinical Practice Guideline 1: recording and analysis of spontaneous cerebral activity. J Clin Neurophysiol Off Publ Am Electroencephalogr Soc 28:348-354. https://doi.org/10.1097/WNP. Ob013e3182272fed

5. Brodie MJ, Barry SJE, Bamagous GA et al (2012) Patterns of treatment response in newly diagnosed epilepsy. Neurology 78:1548-1554. https://doi. org/10.1212/WNL.0b013e3182563b19

6. De Tiège $X$, Carrette $E$, Legros B et al (2012) Clinical added value of magnetic source imaging in the presurgical evaluation of refractory focal epilepsy. JNeurol Neurosurg Psychiatry 83:417-423. https:// doi.org/10.1136/jnnp-2011-301166

7. De Tiège $X$, Lundqvist $D$, Beniczky $S$ et al (2017) Current clinical magnetoencephalography practice across Europe: Are we closer to use MEG as an established clinical tool? Seizure 50:53-59. https://doi.org/10.1016/j.seizure.2017.06.002

8. Engel J, McDermott MP, Wiebe S et al (2012) Early surgical therapy for drug-resistant temporal lobe epilepsy: a randomized trial. JAMA, vol 307, pp 922-930 https://doi.org/10.1001/jama.2012.220 


\section{Leitthema}

9. Genow A, HummelC, Scheler Getal (2004) Epilepsy surgery, resection volume and MSI localization in lesional frontal lobe epilepsy. Neuroimage 21:444-449

10. Heers M, RamppS, Stefan Het al (2012) MEG-based identification of the epileptogenic zone in occult peri-insular epilepsy. Seizure 21:128-133. https:// doi.org/10.1016/j.seizure.2011.10.005

11. Itabashi H, Jin K, Iwasaki M et al (2014) Electroand magneto-encephalographic spike source localization of small focal cortical dysplasia in the dorsal peri-rolandic region. Clin Neurophysiol Off J Int Fed Clin Neurophysiol 125:2358-2363. https:// doi.org/10.1016/j.clinph.2014.02.028

12. de Jongh A, de Munck JC, Gonçalves SI, Ossenblok $P$ (2005) Differences in MEG/EEG epileptic spike yields explained by regional differences in signalto-noise ratios. J Clin Neurophysiol Off Publ Am Electroencephalogr Soc 22:153-158

13. Kakisaka Y, Iwasaki M, Alexopoulos AV et al (2012) Magnetoencephalography in fronto-parietal opercular epilepsy. Epilepsy Res 102:71-77. https://doi.org/10.1016/j.eplepsyres.2012.05.003

14. Knowlton RC, Elgavish R, Howell J et al (2006) Magnetic source imaging versus intracranial electroencephalogram in epilepsy surgery: A prospective study. Ann Neurol 59:835-842. https://doi.org/10.1002/ana.20857

15. Knowlton RC, Elgavish RA, Bartolucci A et al (2008) Functional imaging: II. Prediction of epilepsy surgery outcome. Ann Neurol 64:35-41. https:// doi.org/10.1002/ana.21419

16. Knowlton RC, Razdan SN, Limdi N et al (2009) Effect of epilepsy magnetic source imaging on intracranial electrode placement. Ann Neurol 65:716-723. https://doi.org/10.1002/ana.21660

17. Marras CE, Canevini MP, Colicchio G et al (2013) Health Technology Assessment report on the presurgical evaluation and surgical treatment of drug-resistant epilepsy. Epilepsia 54(7):49-58. https://doi.org/10.1111/epi.12309

18. Mohamed IS, Gibbs SA, Robert M et al (2013) The utility of magnetoencephalography in the presurgical evaluation of refractory insular epilepsy. Epilepsia 54:1950-1959. https://doi.org/ 10.1111/epi.12376

19. Mohamed IS, Otsubo H, Ochi A et al (2007) Utility of Magnetoencephalography in the Evaluation of Recurrent Seizures after Epilepsy Surgery. Epilepsia 48:2150-2159. https://doi.org/10.1111/ j.1528-1167.2007.01271.x

20. Mouthaan BE, Rados M, Barsi P et al (2016) Current use of imaging and electromagnetic source localization procedures in epilepsy surgery centers across Europe. Epilepsia 57:770-776. https://doi. org/10.1111/epi.13347

21. Mu J, Rampp S, Carrette E et al (2014) Clinical relevance of source location in frontal lobe epilepsy and prediction of postoperative longterm outcome. Seizure 23:553-559. https://doi. org/10.1016/j.seizure.2014.04.006

22. Muthaffar O, Puka K, Rubinger L et al (2017) Reoperation after failed resective epilepsy surgery in children. J Neurosurg Pediatr 20:134-140. https://doi.org/10.3171/2017.3.PEDS16722

23. Nguyen DK, Nguyen DB, Malak R et al (2009) Revisiting the role of the insula in refractory partial epilepsy. Epilepsia 50:510-520. https://doi.org/ 10.1111/j.1528-1167.2008.01758.x

24. Park H-M, Nakasato N, Tominaga T (2012) Localization of abnormal discharges causing insular epilepsy by magnetoencephalography. Tohoku JExp Med 226:207-211
25. Perry MS, Duchowny M(2013) Surgical versus medical treatment for refractory epilepsy: outcomes beyond seizure control. Epilepsia 54:2060-2070. https://doi.org/10.1111/epi.12427

26. Rosenow F, Lüders H (2001) Presurgical evaluation of epilepsy. Brain, vol 124, pp 1683-1700 https:// doi.org/10.1093/brain/124.9.1683

27. Ryvlin P, Minotti L, Demarquay G et al (2006) Nocturnal hypermotor seizures, suggesting frontal lobe epilepsy, can originate in the insula. Epilepsia 47:755-765. https://doi.org/10.1111/j.15281167.2006.00510.x

28. Sommer B, Roessler K, Rampp S et al (2016) Magnetoencephalography-guided surgery in frontal lobe epilepsy using neuronavigation and intraoperative MR imaging. Epilepsy Res 126:26-36. https://doi.org/10.1016/j.eplepsyres. 2016.06.002

29. Spencer S, Huh L (2008) Outcomes of epilepsy surgery in adults and children. Lancet Neurol 7:525-537. https://doi.org/10.1016/s14744422(08)70109-1

30. Stefan H, Hummel C, Scheler G et al (2003) Magnetic brain source imaging of focal epileptic activity: a synopsis of 455 cases. Brain J Neurol 126:2396-2405. https://doi.org/10.1093/brain/ awg239

31. Stefan H, Scheler G, Hummel C et al (2004) Magnetoencephalography (MEG) predicts focal epileptogenicity in cavernomas. J Neurol Neurosurg Psychiatry 75:1309-1313. https://doi. org/10.1136/jnnp.2003.021972

32. Stefan H, Trinka E (2017) Magnetoencephalography (MEG): Past, current and future perspectives for improved differentiation and treatment of epilepsies. Seizure 44:121-124. https://doi.org/ 10.1016/j.seizure.2016.10.028

33. Stefan H, Wu X, Buchfelder M et al (2011) MEG in frontal lobe epilepsies: Localization and postoperative outcome. Epilepsia 52:2233-2238. https://doi.org/10.1111/j.1528-1167.2011.03265. $\mathrm{x}$

34. Surges R, Elger CE (2013) Reoperation after failed resective epilepsy surgery. Seizure 22:493-501. https://doi.org/10.1016/j.seizure.2013.04.020

35. Sutherling WW, Mamelak AN, Thyerlei $D$ et al (2008) Influence of magnetic source imaging for planning intracranial EEG in epilepsy. Neurology 71:990-996. https://doi.org/10.1212/01.wnl. 0000326591.29858.1a

36. Tanaka N, Peters JM, Prohl AK et al (2014) Clinical value of magnetoencephalographic spike propagation represented by spatiotemporal source analysis: correlation with surgical outcome. Epilepsy Res 108:280-288. https://doi.org/10. 1016/j.eplepsyres.2013.11.006

37. Téllez-Zenteno JF, Dhar R, Wiebe S (2005) Longterm seizure outcomes following epilepsy surgery: a systematic review and meta-analysis. Brain J Neurol 128:1188-1198. https://doi.org/10.1093/ brain/awh449

38. Trinka E, Kreidenhuber R, Leitinger M (2016) Ergänzungen zur prächirurgischen Diagnostik bei Epilepsiepatienten https://doi.org/10.1007/ s10309-016-0081-2

39. Wang Y, Liu B, Fu L, Cui Z (2015) Use of interictal (18)F-fluorodeoxyglucose (FDG)-PET and magnetoencephalography (MEG) to localize epileptogenic foci in non-lesional epilepsy in a cohort of 16 patients. J Neurol Sci 355:120-124. https://doi.org/10.1016/j.jns.2015.05.039

40. Wang ZI, Alexopoulos AV, Jones SE et al (2014) Linking MRI postprocessing with magnetic source imaging in MRI-negative epilepsy. Ann Neurol 75:759-770. https://doi.org/10.1002/ana.24169

41. Wiebe S, Blume WT, Girvin JP, Eliasziw M (2001) A Randomized, Controlled Trial of Surgery for Temporal-Lobe Epilepsy. N Engl J Med 345:311-318. https://doi.org/10.1056/NEJM200108023450501 